\title{
"Don't Drink the Water"
}

\section{The Camp Lejeune Water Contamination Incident}

\author{
Laurel Beckley-Jackson
}

$\mathbf{F}$ rom 1953 until 1987, an estimated one million Marines and their families at Marine Corps Base Camp Lejeune, North Carolina, were exposed to drinking water contaminated with several volatile organic compounds (VOCs) known to cause cancer and other serious health conditions. ${ }^{1}$ From the time of detection in 1980 until a Congressional mandate in 2007, the Marine Corps made little to no effort to notify the affected veterans and their families of the potential for health problems, and failed to fully disclose the true extent of the contamination.

The story of the Camp Lejeune water contamination incident is told through government and civilian documents made available largely by the dedicated efforts of a small group of Camp Lejeune veterans and their children. For government documents librarians and researchers, this offers guidance in researching the laws and regulations around water contamination incidents.

\section{Background}

Established in 1941, Camp Lejeune is the largest Marine Corps base in the United States. In addition to the military commands, training centers, motor pools and disposal dumps, the base has day care centers, schools, nine family housing areas, gyms, libraries, administrative offices, a shopping center and a hospital. Until 1985, it had eight water systems fed by more than one hundred wells. ${ }^{2}$

Drinking water standards beyond water clarity and general sanitation weren't federally mandated until the Safe Drinking Water Act of 1974 (P.L. 93-523), which set maximum allowable standards for twenty-eight different substances. In 1979, due to new research on the harmful effects of VOCs, an interim standard to the Act was issued requiring testing of all community water sources for a VOC called trihalomethane (TTHM). ${ }^{3}$ The Department of Defense tried to get an exemption to the new requirement, claiming inadequate resources to conduct the tests. They were denied.
On October 1, 1980, an official with Navy Facilities Engineering Command, Atlantic Division (LANTDIV), took samples from all eight Camp Lejeune water treatment plants, combined them into one sample and sent it to a private lab for testing. ${ }^{4}$ Another sample was drawn October 21, 1981. Instead of finding TTHM or better yet, nothing, accurate readings of TTHM were obscured by high concentrations of one or more unknown VOCs. These interfering VOCs turned out to be: trichloroethylene (TCE), a solvent usually used in metal degreasers; tetrachloroethylene (PCE), used in dry cleaning solvents; and benzene, a fuel component. At the time of detection, neither TCE nor PCE were federally regulated, but each had well known health risks. ${ }^{5}$

The source of the VOCs was slowly narrowed down to two water treatment systems: Hadnot Point (located near a waste dump and underground storage tanks) and Tarawa Terrace (located at the northern edge of Camp Lejeune). ${ }^{6}$

According to the Government Accountability Office's (GAO) 2007 report, "Activities Related to Past Drinking Water Contamination at Camp Lejeune," in the 1970s and 1980s the Tarawa Terrace water system (established 1952) served an annual average of 5,814 people and the Hadnot Point system (established 1942) served an annual average of seventy-one people, in addition to schools, an industrial area, recreational areas, and the base hospital. ${ }^{7}$ From 1942 until 1971, Hadnot Point also provided water to the Holcomb Boulevard Residential Area. ${ }^{8}$

Samples continued to be taken from the Tarawa Terrace and Hadnot Point water treatment plants from 1980 until 1984. Pointed warnings from the labs were issued and disregarded by Camp Lejeune officials, including one from March 9, 1981, stating, "Water highly contaminated with other chlorinated hydrocarbons (solvents)!" "This memo was the fourth warning to officials. Based on recommendation from LANTDIV that further data was needed from the TTHM testing and a planned Naval 
Assessment and Control of Installation Pollutants (NACIP) study, no corrective action was taken. ${ }^{10}$

Monthly samples were collected from April 1982 until August 18, 1982, when Camp Lejeune officials inexplicably changed to quarterly samples, the Department of Defense standard. In the same month, the base commanding general received a memo from the base chemist expressing health concerns over the water quality, based on the initial October 1, 1980, sample. ${ }^{11}$

Compounding problems, readings from the water treatment plants were wildly erratic. These inconsistent results, where a sample would be high as 1,400 parts per billion (ppb) TCE one month and plummet to $5 \mathrm{ppb}$ in the next, was later attributed to the rotation of wells that mixed and diluted contaminated wells with uncontaminated wells. ${ }^{12}$ The variances made finding a baseline of contamination challenging.

In July 1984, individual wells were finally tested for contamination, as part of LANTDIV's Naval Assessment and Control of Installation Pollutants (NACIP) Confirmation Study. When the results returned, ten of the forty tested wells were contaminated: eight at Hadnot Point and two at Tarawa Terrace tested positive for both TCE and PCE, and all wells at Hadnot Point had some level of benzene. ${ }^{13}$ The highest benzene contamination, at well HP-602, read 380 ppb-incorrectly written as 38 ppb in subsequent reports. ${ }^{14}$

The ten contaminated wells were removed from rotation from November 30, 1984, to February 8, 1985, as a result of the July 1984 tests. However, the wells were used intermittently through 1987 to supplement low water levels. ${ }^{15}$ By 1987, the contaminated wells at Hadnot Point and Tarawa Terrace were permanently closed. Unfortunately for Camp Lejeune residents, the closure was only the beginning.

\section{Public Notification and Initial Studies: 1985-99}

Seven months after the initial closure of the wells in 1985, nineyear-old Janey Ensminger succumbed to her three-year battle with leukemia in a Pennsylvanian hospital. Her father, Marine Jerry Ensminger, was in shock. Neither his nor his wife's family had a history of childhood leukemia, and his three other children were healthy. ${ }^{16}$ There seemed to be no rhyme or reason for Janey's illness and death.

The public first learned of issues with the water system in a June 1984 base newsletter titled, "Environmental Study Kicks Off," which announced the beginning of the NACIP Confirmation study. This article, like several released at the time, downplayed the extent of the exposure, stressing that officials "did not expect to expose anyone to any contaminants." ${ }^{17}$
In April 1985, base residents were notified ten wells had been closed as a precautionary measure due to the discovery of "trace amounts" of contaminants. ${ }^{18}$

These notifications were limited to those Marines and their families stationed at Camp Lejeune, and to local media reports. Families who had moved out of the area would wait decades for official notification. Some would watch Dan Rather's 1997 newscast regarding the contamination. Jerry Ensminger was one of those watching the reports, and he reported that it was as though the ceiling caved in-Janey had been conceived and born on Camp Lejeune. ${ }^{19}$ Ensminger began to hunt for answers, which were not easily forthcoming.

Misinformation wasn't just limited to the public. Camp Lejeune, LANTDIV, and Department of the Navy officials doled bits and pieces to various state and federal officials. Upon request from Camp Lejeune officials, the North Carolina Department of Natural Resources and Community Development conducted an investigation into a suspected offbase pollutant of the water supply. This 1985 report determined that the source of Tarawa Terrace's PCE contamination from ABC One-Hour Cleaners, an off-base dry-cleaners. It had been in operation since 1953, slowly polluting three wells in the Tarawa Terrace water supply system. ${ }^{20}$ Uninformed of the actual extent of the contamination and thinking it had been discovered in 1984, the head of the North Carolina Water Supply branch stated, "Camp Lejeune should not worry about getting bad drinking water. I think we kind of caught it at the beginning. It's not something that has been running for two or three years." 21

With the discovery of an off-base scapegoat, the other contaminations - TCE and benzene-at Tarawa Terrace and Hadnot Point fell to the wayside. Later reports determined the TCE had seeped into wells located within one hundred meters of equipment dumping grounds. ${ }^{22}$ The 1988 discovery of a massive leak within underground fuel tanks, at a rate of 1,500 gallons per month (creating a 1.1 million gallon gasoline lake on top of the Camp Lejeune groundwater), caused a moment of alarm. ${ }^{23}$ These fuel tanks were dangerously close to several Hadnot Point wells and were the source of the high levels of benzene in HP-602. The fuel spill and resulting benzene contamination quickly became supplanted in Marine Corps press releases by reports of the $\mathrm{ABC}$ One-Hour Cleaners' contamination of the Tarawa Terrace wells.

Federal agencies stepped in to deal with the clean-up of the contaminated areas. In 1988, the Department of the Navy requested that the recently formed Agency for Toxic Diseases and Registry (ATSDR) conduct a public health assessment (PHA) on ABC One-Hour Cleaners and Camp Lejeune. The 
Environmental Protection Agency (EPA) placed Camp Lejeune on the National Priorities List in 1989, designating it as a Superfund Site. TCE and PCE became regulated under the 1989 and 1992 Safe Drinking Water Act amendments, respectively. ${ }^{24}$ Little progress was made on any study or clean-up throughout the early 1990s, mostly due to Marine Corps stonewalling and the ATSDR's lack of funding from the Department of the Defense. ${ }^{25}$

The ATSDR's much delayed Camp Lejeune PHA was published in 1997 and formed the basis for numerous studies, Congressional hearings, federal reports and an EPA-led criminal investigation. This report listed the VOC contamination of TCE and PCE as second of three past public health hazards at Camp Lejeune. It failed to address the extent of the benzene contamination at Hadnot Point. Most damningly, the 1997 Camp Lejeune PHA stressed the unlikelihood of adverse health effects on adults and children exposed to TCE and PCE. ${ }^{26}$

The 1997 PHA did stress a concern for the potential of damage to developing fetuses exposed to the VOCs, however. In the 1998 document, "Volatile Organic Compounds in Drinking Water and Adverse Pregnancy Outcomes," the ATSDR analyzed the birth certificates of 11,970 children born at Camp Lejeune to determine possible correlations between mean birth weights and VOC exposure. ${ }^{27}$ Not surprisingly, the agency found that birth certificates contained little information. The agency decided to conduct another study, one that would contact families directly for information. There was a problem: the names resided with the Marine Corps, who had proven reluctant to provide timely information.

The resulting notification was the first individual notification of the exposure-limited to those families with children born on the base between 1968 and $1985 .{ }^{28}$ One of these children was Mike Partain, who had been diagnosed with male breast cancer. When he learned of his possible exposure, everything clicked into place. Through his own research, Partain found Ensminger and joined his advocacy group, The Few, The Proud, The Forgotten (TFTPTF).

In response to increasing demands from the publicparticularly the TFTPTF - the Commandant of the Marine Corps convened a Blue Panel in 2004 to investigate. This report reiterated what had become the official Marine Corps story: in keeping with federal drinking water regulations at the time, Camp Lejeune officials closed the wells upon discovery of the contamination. ${ }^{29}$

"Trying to pin down the truth with the leadership of the Marine Corps is like trying to nail Jell-O to a wall," said Partain. ${ }^{30}$ The dispensing of information was limited to highly edited reports provided on Marine Corps and ATSDR websites.
This lack of information led Ensminger and Partain to conduct their own research, submitting numerous Freedom of Information Act requests to the Marine Corps, ATSDR, EPA, National Academy of Sciences, LANTDIV and other federal agencies. They also reached out to former residents, urging them to write to their Congressmen to demand action.

\section{Congress Steps In}

Slowly, Congress began to move. A bipartisan amendment to the 2007 Defense Authorization Act directed the National Academy of Sciences to conduct a study evaluating the strength of the link between TCE and PCE exposure and adverse health impacts for prenatal, childhood and adult exposures at Camp Lejeune. ${ }^{31}$ Frustrated over the Marine Corps' failure to notify all possibly exposed Camp Lejeune residents, Senator Jeffords ensured the bill ordered the Marine Corps to begin official notifications. ${ }^{32}$

Following intense lobbying by TFTPTF, official hearings on the contamination began in 2007. "Poisoned Patriots: Contaminated Drinking Water at Camp Lejeune" concentrated primarily on two reports, the ATSDR's 1997 Camp Lejeune PHA and a freshly released GAO investigation. The latter report took much of its data from the flawed 1997 PHA, a fact repeatedly stressed by Ensminger at the hearing. ${ }^{33}$ Due to this, the benzene contamination, which had dropped from media attention and most official reports, was not mentioned. Little resulted from the hearing beyond an ATSDR feasibility study on cancer and adverse health effects in exposed adults and children. ${ }^{34}$

Suddenly, in 2009, the ATSDR announced they had stumbled across documents they claimed were previously undisclosed by the Marine Corps (proved untrue by multiple early versions of the 1997 Camp Lejeune PHA). ${ }^{35}$ These documents revealed the real levels of benzene detected at well HP-602, which Secretary of the Navy Ray Mabus admitted had been "erroneously transcribed" without "intentional misrepresentation." ${ }^{36}$ As a result of the benzene rediscovery, the ATSDR cancelled the 1997 Camp Lejeune PHA, the first time a PHA had been withdrawn since the agency was founded in $1986 .{ }^{37}$

The benzene reveal opened the door for another hearing on September 16, 2010, before the House Subcommittee on Investigations and Oversight of the Committee on Science and Technology: "Camp Lejeune: Contamination and Compensation, Looking Back, Moving Forward." Confronted with overwhelming evidence presented by the members of TFTPTF, the ATSDR and other agencies, the Marine Corps finally admitted responsibility after years of stonewalling. "It is astounding some of the things that happened, and I think they 
happened for a number of reasons," said Marine Major General Payne. "I think we were ignorant, quite frankly, of some of the implications. I think we were lulled into a sense of complacency or at least a lack of urgency by the fact that we were not out of compliance. And I am not trying to excuse what happened. I think that there were many, many errors made on behalf of the Marine Corps." 38

To date, no single person has been charged with connection to the contamination or the delayed closure of the wells.

\section{Compensation}

Veterans and their families had been submitting claims to the Department of Veteran's Affairs (VA) seeking care and reimbursement for medical conditions that seemed to stem from their time in Camp Lejeune since the late 1980s. By September 2010, only twenty of more than two hundred claims had been approved by the VA, with the majority of the disapprovals stemming from a lack of substantiation that Camp Lejeune's water had caused the condition. ${ }^{39}$

To provide some compensation and force the VA to quickly admit exposed veterans, S. 1518 "Caring for Camp Lejeune Veterans Act of 2009" was introduced by Senator Richard Burr on October 21, 2009, ${ }^{40}$ while the House introduced H.R. 4555, or "The Janey Ensminger Act," on February 2, 2010. ${ }^{41}$ Neither S. 1518 nor H.R. 4555 was passed into law. A third bill, H.R. 1627, was introduced on 15 April 2011.

On August 6, 2012, twenty-five years after the final closure of the contaminated wells at Camp Lejeune, H.R. 1627 became PL 112-154. Active duty veterans and their families who served at Camp Lejeune for more than thirty days from January 1, 1957, until December 31, 1987, became "eligible for hospital care and medical services" through the VA for fifteen conditions, "notwithstanding insufficient medical evidence to conclude that the illness or condition is attributable to such service. $^{.42}$

\section{Conclusion}

The story doesn't end with PL 112-154. Although the law acknowledged that the mysterious illnesses plaguing Camp Lejeune veterans and their families was not random, it did not erase the five years of inaction and subsequent decades of silence from the Marine Corps. Many veterans felt a deep sense of betrayal from an organization that stresses, "No Marine left behind" and "Semper Fidelis," Latin for "always faithful." Additionally, every former resident or employee at Camp Lejeune from 1953 until 1987 lives with the consequences of their exposure-the healthy will forever wonder when their turn will come.
The ATSDR and other agencies continue to study the adverse health effects of by victims who lived and worked at Camp Lejeune. In 2014, the ATSDR completed the "Evaluation of mortality among Marines and Navy personnel exposed to contaminated drinking water at USMC Base Camp Lejeune: A retrospective cohort study," which found "an increased risk of death in the Camp Lejeune cohort for several causes including cancers of the cervix, esophagus, kidney, and liver, Hodgkin's lymphoma, and multiple myeloma. ${ }^{343}$ Another ATSDR study in 2015 reluctantly linked 64 instances of male breast cancerincluding Mike Partain - to the water contamination. ${ }^{44}$

Jerry Ensminger, Mike Partain and the rest of TFTPTF continue to advocate for the rights of Camp Lejeune victims. Despite facing set-back after set-back, they proved that ordinary citizens can find justice and compensation against environmental and health contamination. Thanks to their diligent Freedom of Information requests, interviews and extensive research and head-hunting, their website, thefewtheproudtheforgotten.com remains the best source of information regarding the contamination. In 2011 TFTPTF produced a documentary chronicling the contamination.

Overall, the Department of Defense owns 141 Superfund sites on the EPA's National Priority List for contaminated areas, making it the largest polluter in the United States. ${ }^{45}$ Camp Lejeune, one of the worse drinking water contamination incidents in United States history, is just the tip of the iceberg.

Laurel Beckley-Jackson (Ib15s@my.fsu.edu), Master of Science in Information Student, Florida State University.

\section{References}

1. US Congress, House Committee on Science and Technology, Camp Lejeune Contamination and Compensation, Looking Back, Moving Forward: Hearing before the Subcommittee on Investigations and Oversight, Committee on Science and Technology, House of Representatives, One Hundred Eleventh Congress, Second Session, September 16, 2010, 111th Cong., 2d sess. SuDoc. Y 4.SCI 2:111-108 (Washington: US GPO, 2010), 4.

2. US Government Accountability Office, Defense Health Care Activities Related to past Drinking Water Contamination at Marine Corps Base Camp Lejeune: Report to Congressional Committees, GAO-07-276, SuDoc. GA 1.13:GAO-07-276 (Washington, DC: US GAO, 2007), 10.

3. Ibid., 26. 
4. US Congress, House Committee on Energy and Commerce, Poisoned Patriots: Contaminated Water at Camp Lejune, Hearing Before the Subcommittee on Oversight and Investigations, House of Representatives, One Hundred Tenth Congress, First Session, June 12, 2010, 110th Cong., 1 sess. SuDoc Y4.C73/8:110-56 (Washington, DC: US GPO, 2007), 4.

5. Camp Lejeune: Contamination and Compensation, 3.

6. Government Accountability Office, Defense Health Care Activities, 20.

7. Ibid., 13.

8. US Agency for Toxic Substances and Disease Registry, Division of Health Studies, An Assessment of the Feasibility of Conducting Future Epidemiological Studies at USMC Base Camp Lejeune, by Frank J. Bove and Perri Z. Ruckart (Atlanta: ATSDR, 2008), 2.

9. "Camp Lejeune Hadnot Point," Tftptf.com, accessed April 3, 2016, https://www.flickr.com/photos/137615361@ N04/22970303144/in/dateposted/.

10. Government Accountability Office, Defense Health Care Activities, 23.

11. Camp Lejeune: Contamination and Compensation, 8.

12. US Agency for Toxic Substances and Disease Registry, ATSDR's Current Health Study at Marine Corps Base Camp Lejeune, NC Use of Water-modeling Methods: ATSDR's Current Health Study at Marine Corps Base Camp Lejeune, NC Use of Water-modeling Methods, by Morris L. Maslia, SuDoc. HE 20.502:L 53/3 (Wilmington, DE: ATSDR, 2007).

13. Government Accountability Office, Defense Health Care Activities, 20.

14. "Letter From Secretary of the Navy to Representative Miller," Ray Mabus to Honorable Brad Miller, Chairman, Subcommittee on Investigations and Oversight, March 17, 2010.

15. US Agency for Toxic Substances and Disease Registry, ATSDR's Current Health Study at Marine Corps Base Camp Lejeune.

16. Semper Fi: Always Faithful homepage, accessed July 13, 2016, http://semperfialwaysfaithful.com/.

17. "Environmental Study Kicks Off," Tftptf.com, accessed April 3, 2016, https://www.flickr.com/photos /137615361@N04/22972590463/in/dateposted/.

18. Ronald C. Packard, Drinking Water Fact-Finding Panel For Camp Lejeune. Report to the Commandant 6 Oct 2004 (Washington, DC: USMC, 2004), 39, http://tftptf.com /images/USMCPanel06Oct2004.pdf.

19. Semper Fi: Always Faithful.
20. Rick Shiver, Summary Report: A Groundwater Investigation to Define the Source(s) of Tetracholoroeti-iylene That Have Contaminated Three Community Water Supply Wells At Tarawa Terrace I Camp Lejeune Marine Corps Marine Base Onslow County, Report no. CLW 004826, North Carolina Department of Natural Resources and Community Development, 1985, accessed April 3, 2016, http://tftptf.com/images/ShiverReport_TT_Cont_1985 .pdf, 39.

21. Packard, $\mathrm{p} 43$.

22. Camp Lejeune: Contamination and Compenstation, 7.

23. Camp Lejeune: Contamination and Compensation, 22.

24. Government Accountability Office, Defense Health Care Activities, 16.

25. Ibid., 3 .

26. US Agency for Toxic Substances and Disease Registry, Federal Facilities Assessment Branch, Division of Health Assessment and Consultation, Public Health Assessment for U.S. Marine Corps Camp Lejeune Military Reservation Camp Lejeune, Onslow County, North Carolina, NC6 170022580 (Atlanta, GA: Agency for Toxic Substances and Disease Registry, 1997), 2, http://tftptf.com/images /CL_PHA_1997.pdf.

27. US Agency for Toxic Substances and Disease Registry, Department of Health and Human Services, Volatile Organic Compounds in Drinking Water and Adverse Pregnancy Outcomes, PB98-156540 (Atlanta: ATSDR, 1998), www.atsdr.cdc.gov/HS/lejeune/.

28. Poisoned Patriots, 26.

29. Packard, Drinking Water Fact-Finding Panel For Camp Lejeune, 40.

30. Camp Lejeune: Contamination and Compensation, p20.

31. US Senate Committee on Environment and Public Works, "Dole, Jeffords' Camp Lejeune Amendment Passes Sensate in DOD Bill," press release, June 22, 2006, US Senate Committee on Environment and Public Works, www.epw.senate.gov/public/index.cfm/press -releases-democratic?ID=1C7C9953-987D-4290-BBB9 -F6EEF386BEA5.

32. Jim Jeffords, "U.S. Marine Corps Base Camp Lejeune Water Contamination." US Congress, Congressional Record, 78th ed., vol. 152, S6004 (Washington: US GPO, 2006).

33. Poisoned Patriots, 27.

34. US Agency for Toxic Substances and Disease Registry, An Assessment of the Feasibility of Conducting Future Epidemiological Studies at USMC Base Camp Lejeune, iii.

35. Camp Lejeune: Contamination and Compensation, 3. 
36. "Letter From Secretary of Navy to Representative Miller."

37. Camp Lejeune: Contamination and Compensation, 105

38. Ibid., 90

39. Ibid., 85

40. Caring for Camp Lejeune Veterans Act of 2009, S.S. 1518, 111th Cong., Congress.gov (2009).

41. Janey Ensminger Act, H.R. 4555, 111th Cong., Congress.gov (2010).

42. An Act to Amend Title 38, United States Code, to Furnish Hospital Care and Medical Services to Veterans Who Were Stationed at Camp Lejeune, North Carolina, while the Water Was Contaminated at Camp Lejeune, to Improve the Provision of Housing Assistance to Veterans and Their Families, and for Other Purposes, Pub. L. No. 112th-PL 112-154, 126 (GPO 2012).
43. Frank J. Bove, Perri Z. Ruckart, and Morris L. Maslia, "Evaluation of Mortality among Marines and Navy Personnel Exposed to Contaminated Drinking Water at USMC Base Camp Lejeune: A Retrospective Cohort Study," Environmental Health (February 19, 2014), http:// dx.doi.org/10.1186/1476-069X-13-10.

44. Perri Z. Ruckart et al., "Evaluation of Contaminated Drinking Water and Male Breast Cancer at Marine Corps Base Camp Lejeune, North Carolina: A Case Control Study," Environmental Health (September 16, 2015), http://dx.doi.org/10.1186/s12940-015-0061-4.

45. Alexander Nazaryan, "The Department of Defense Is One of the World's Biggest Polluters," Newsweek (July 17, 2016), www.newsweek.com/2014/07/25/us-department -defence-one-worlds-biggest-polluters-259456.html. 